\title{
The Effect of an Educational Intervention on Adherence to Intraocular Pressure-Lowering Medications in a Large Cohort of Older Adults with Glaucoma
}

\author{
Richard Fiscella, PharmD, MPH; Eleanor Caplan, PharmD, PhD; Pravin Kamble, RPh, PhD; \\ Suvapun Bunniran, PhD; Claudia Uribe, MD, PHA, PhD; and Hitesh Chandwani, MBBS, PhD
}

\begin{abstract}
BACKGROUND: Glaucoma is a progressive, irreversible disease that can lead to vision loss and lower quality of life if treatment is not optimized. Effective glaucoma therapies are available to lower intraocular pressure (IOP) and minimize or delay disease progression. Nonetheless, adherence to treatment remains suboptimal for many patients.

OBJECTIVE: To identify potentially nonadherent patients and evaluate the effect of patient- and physician-centric educational interventions on adherence by using a validated predictive model of nonadherence to glaucoma medication.

METHODS: This prospective, randomized, controlled, and interventional study included Humana Medicare Advantage Prescription Drug plan patients with a glaucoma diagnosis between May and October 2014, $\geq 1$ pharmacy claim for glaucoma medication, and $\geq 50 \%$ likelihood of nonadherence. Patients and physicians were randomized to cohorts A (no interventions), B (physician intervention), or C (patient and physician interventions). Physicians in cohorts $B$ and $C$ received information on the model, adherence, and patient profiles at baseline and months 3,6, and 9. Patients in cohort $C$ received educational materials on glaucoma and adherence (same schedule). The primary outcome was the proportion of days covered (PDC) with medication over 12 months. Adherence was defined as $\mathrm{PDC} \geq 0.80$.
\end{abstract}

RESULTS: Overall, 23,306 patients and 2,955 physicians were eligible. After excluding physicians with $<3$ nonadherent patients, each cohort included 200 physicians and 600 patients. Mean PDC was 0.54-0.56 across cohorts. At 12 months, $\geq 90.5 \%$ of physicians and $\geq 75.5 \%$ of patients remained in the study; mean PDC was $0.53-0.54$ across cohorts. No statistically significant between-cohort differences in PDC and adherence were observed.

CONCLUSIONS: Intensive educational mailings to patients and their physicians did not improve PDC or adherence in this large population of potentially nonadherent patients with glaucoma. Findings highlight the difficulty of improving adherence in a disease that requires lifelong therapy despite being largely asymptomatic and can inform development of future interventions aimed at improving adherence to glaucoma therapy.

J Manag Care Spec Pharm. 2018;24(12):1284-94

Copyright $\odot 2018$, Academy of Managed Care Pharmacy. All rights reserved.

\section{What is already known about this subject}

Interventions aimed at improving adherence to glaucoma therapy, such as daily voice or text messages reminding patients to take their medication, or combination of educational videos, regular phone calls, and dosing-aid activated reminders, have been shown to be effective in small $(\mathrm{n} \leq 70)$ randomized studies of patients with glaucoma set in university subspecialty clinics or eye institutes.

From a physician's perspective, however, such interventions may be impractical given the prevalence of the disease.

\section{What this study adds}

Using a validated and peer-reviewed predictive model of nonadherence to glaucoma medication to identify potentially nonadherent patients enrolled in a large U.S.-based health care company, this study shows that a multifaceted approach that included repeated mailings of educational materials specifically adapted for patients and their physicians over a 12-month period did not significantly improve adherence to treatment.

Study findings illustrate the difficulty of improving adherence to treatment using interventions designed to be practical and applicable in large populations when the disease is chronic and typically asymptomatic until late stages.

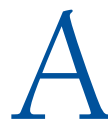
lthough effective glaucoma treatment approaches are available to lower intraocular pressure (IOP) and minimize disease progression that can otherwise lead to vision loss and lower quality of life, adherence to medications remains suboptimal for many patients, and its negative effect on visual field has been reported. ${ }^{1-8}$ Numerous factors have been implicated in nonadherence, such as older age, the cost of medication, inconvenience of frequent administration, and lack of symptoms until late disease stage. ${ }^{2-7}$ Interventions aimed at improving adherence have been shown to be effective in randomized studies of patients with glaucoma $(n \leq 256)$ set in university subspecialty clinics or eye institutes in the United States. ${ }^{9-11}$ These interventions have included single approaches, such as daily voice or text messages reminding patients to take their medication; multifaceted ones, such as a combination of 
educational videos, regular phone calls, and dosing-aidactivated reminders; or a customized letter and personal telephone call from the researcher. ${ }^{9-11}$ From a physician's perspective, however, interventions such as sending daily texts to all patients who are prescribed IOP-lowering medication (or having to keep track of the information generated by those interventions up to 3 times a day, if automated) may be impractical given the incidence and prevalence of the disease. ${ }^{12,13}$ Moreover, nonadherence is a multifactorial issue, and although automated reminders would be expected to help address barriers to adherence such as forgetfulness and difficulty with the treatment schedule, other important barriers (e.g., poor knowledge and difficulty with drop administration) are likely to benefit more from educational information and/ or interaction with the health care providers (as suggested by the American Academy of Ophthalmology).,14 Identification of potentially nonadherent patients is thus an important issue; however, identifying potentially nonadherent patients based on demographic or clinical factors, which may be more easily accessed and measured than behavioral and psychological factors, remains a challenge.

Using claims data from a large U.S.-based health care company, a study was recently conducted to identify demographic and clinical factors associated with nonadherence to glaucoma medication in elderly patients. A predictive model was developed (using multivariable logistic regression, a significance level of 0.01 , and a patient sample of $48,840 / 73,256$ ) as a tool to help physicians and payers identify elderly patients at risk of nonadherence..$^{15}$ Baseline variables incorporated in the initial model included demographics (age, gender, race, and geographic region); plan type; low-income subsidy; Rx-Risk-V composite risk score (a pharmacy claims-based comorbidity measure that assesses medical condition burden ${ }^{16}$ ); conditions present (hypertension, hyperlipidemia, diabetes, congestive heart failure, joint disorders, muscle weakness/movement disorders, mental disorders, or glaucoma); glaucoma surgery, glaucoma-related eye exam, or open-angle glaucoma diagnosed by an ophthalmologist; number of physicians seen and pharmacies used; new versus continuing users of IOP-lowering medications; source of prescription (mail order vs. retail, formulary tier, prescriber gender, and prescriber specialty for the index IOP-lowering prescriptions); and preindex medical and pharmacy costs. Of those, 10 factors that were significantly related to nonadherence were incorporated in the final model; 4 significantly increased the likelihood of nonadherence (i.e., index IOP-lowering prescription filled through mail order [available to all individuals with a pharmacy benefit], higher overall medical costs before the study period, being a new user of IOP-lowering medication, and being male), while 6 significantly decreased it (i.e., advanced age, higher pharmacy costs before the study period, receiving low-income subsidy, residing in the southern U.S. Census Bureau region, a previous diagnosis of open-angle glaucoma, and a history of glaucoma surgery). The final model was then validated using the remaining patient sample (i.e., 24,416/73,256) and was shown to perform equally well in the development and validation patient samples (area under the curve $=0.71$ ), suggesting a robust model. ${ }^{15}$ The objective of the present study was to apply this validated, predictive model in a large population of older adults with glaucoma to identify those at risk for nonadherence to IOP-lowering therapy and to evaluate the effect of patientand physician-centric informational and educational interventions on adherence to treatment in this population.

\section{Methods}

\section{Study Design and Participant Selection}

This was a prospective, controlled, and cluster-randomized study (i.e., randomized by treating physician) conducted among patients with glaucoma within a large U.S. health care company. The study protocol was approved by an independent institutional review board (IRB) before study initiation.

The administrative claims database used for this study included enrollment files, medical claims, and outpatient pharmacy claims data from Humana, a U.S.-based health care company that provides Medicare Advantage Prescription Drug (MAPD) plan, standalone Medicare Prescription Drug plan, and commercial health plan offerings. The Humana research database was screened to identify patients with MAPD coverage, aged 65-89 years, who had $\geq 1$ diagnosis of glaucoma (International Classification of Diseases, Ninth Revision, Clinical Modification [ICD-9-CM] code 365.xx [i.e., any type]) and $\geq 1$ pharmacy claim for an IOP-lowering medication between May 1, 2014, and October 31, 2014. For inclusion in the study, patients were also required to be continuously enrolled in the MAPD plan during the 6-month identification period and the preceding 12 months. In addition, during the identification period, all patients and all physicians prescribing the most recent IOP-lowering medication were required to have a valid mailing address. MAPD plan patients in long-term care and elderly patients with a standalone prescription drug plan only were excluded from the study.

From this eligible study sample, patients considered likely to be nonadherent to IOP-lowering medication were selected using the validated predictive nonadherence model described in the Introduction. ${ }^{15}$ The model was fitted with enrollment and medical/pharmacy data from the 6-month identification period to identify potentially nonadherent patients (defined as those with $\mathrm{a} \geq 50 \%$ probability of having medication supply for $<80 \%$ of study days).

Patients included in the study were linked to the physician who prescribed their most recent IOP-lowering medication, and physicians were categorized according to their number of study-eligible patients. In accordance with the planned study inclusion ratio (3 patients per physician), physician selection 


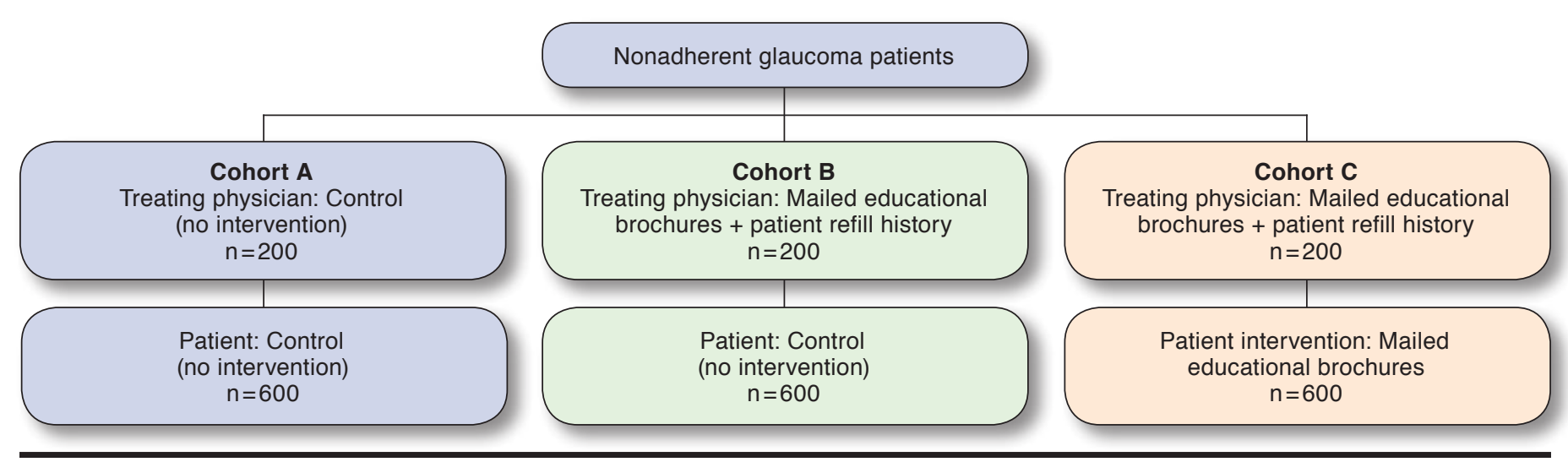

was limited to those treating at least 3 potentially nonadherent patients with glaucoma. Nonadherent patients for whom the patient-to-physician ratio was lower than 3:1 were excluded at this stage. In the event a physician was treating more than 3 potentially nonadherent patients, 3 were randomly selected for that physician to maintain the 3:1 patient-to-physician ratio.

\section{Randomization and Interventions}

From the selected physician and patient populations, 600 physicians were randomly assigned to 1 of 3 cohorts, together with their associated 1,800 patients (Figure 1): cohort A ("usual care" control group in which neither physicians nor patients received interventions), cohort B (interventions directed at physicians only), and cohort C (patients and physicians received interventions). A waiver of consent and authorization for use of administrative data were granted by an independent IRB.

Patients were automatically included in the same cohort as their physician. Physicians assigned to cohorts B and C received (a) a cover letter explaining that they were contacted because a prior study conducted at Humana identified that the physicians had prescribed glaucoma medications for patients who were at high risk of being nonadherent to those medications; (b) a 2-page brochure ("Glaucoma Adherence in Humana's Medicare Population") containing information on adherence to glaucoma medications in the Humana Medicare population, background information on the predictive model (including the predictors of nonadherence), and relevance to clinical practice; and (c) patient-specific clinical and medication profiles (i.e., medication refill history, outpatient visits and procedures, and comorbid conditions). These materials were mailed at baseline and months 3, 6, and 9 for a total of 4 interventions. On the same schedule, patients in cohort $C$ received a cover letter describing the potential effect of glaucoma on their vision and the importance of continued use of IOP-lowering eye drops to prevent disease progression, and a 2-page educational brochure on glaucoma that discussed the importance of adherence to therapy and provided such tips as how to keep track of the treatment schedule, what to do if a dose is missed, how glaucoma medications work, and potential side effects. The content of the materials ("Treating Glaucoma," from the "Understanding and Living with Glaucoma" brochure developed by the Glaucoma Research Foundation ${ }^{17}$ ) was adapted by Comprehensive Health Insights (with permission) for the patients enrolled in Humana's health care programs, and graphic design elements were added to ensure ease of reading and compliance with Humana and Medicare material guidelines.

\section{Study Outcomes}

The primary outcome measure was the proportion of days covered (PDC) with $\geq 1$ IOP-lowering medication (including alpha-agonists [brimonidine, apraclonidine]; beta-blockers [betaxolol, carteolol, levobunolol, metipranolol, timolol]; carbonic anhydrase inhibitors [brinzolamide, dorzolamide]; miotics [carbachol, pilocarpine], prostaglandin analogs/prostamide [bimatoprost, latanoprost, tafluprost, unoprostone]; combinations [brimonidine/timolol, brinzolamide/brimonidine, dorzolamide/timolol]; and others [phospholine iodide, Propine], identified by brand name and generic National Drug Code number) over the 12 months following the date of dispatch of the initial (baseline) intervention (index date: March 26, 2015). The 12-month PDC was calculated by summing the total days' supply of IOP-lowering medication during the first 365-day post-index period and dividing that by 365 days. The interim 6-month PDC was also measured and reported.

For comparison, the PDC with $\geq 1$ IOP-lowering medication over the 12 months immediately preceding the index date (i.e., baseline PDC) was also estimated. The days supply of IOP-lowering medication (days covered) was accessed from prescription fill claims data for each patient. The number of 
days ophthalmic drug supply provided by each prescription fill was determined from published medication drop-count studies that measured the number of drops of drug solution dispensed from commercially available bottles of IOP-lowering medication, together with recommended dose and dosing frequency data. ${ }^{18-20}$ Patients were deemed to be adherent if they had $\geq 144$ and $\geq 292$ days with IOP-lowering medication supply over the 180 -day and 365-day assessment periods, respectively (equivalent to a PDC $\geq 0.80$ ).

\section{Covariates and Other Measures}

Demographic characteristics (age, sex, race, and geographic region of residence) and health plan characteristics (e.g., plan type, low-income subsidy status) were reported based on enrollment data available at the identification date.

Clinical characteristics and glaucoma measures were also described in the baseline period, including Rx-Risk-V score, ${ }^{16}$ the proportion of patients with common comorbidities identified by Rx-Risk-V categories (e.g., hypertension, hyperlipidemia, diabetes, congestive heart failure), and comorbidities that may interfere with application of topical glaucoma medications (e.g., joint disorders, movement disorders, mental disorders). Additionally, whether the patient had a documented diagnosis of open-angle glaucoma by an ophthalmologist, an eye exam (by any physician), a glaucoma-related eye exam, and evidence of any type of glaucoma surgery were recorded.

Prescription utilization measures (e.g., new IOP-lowering medication user [i.e., no claims for an IOP-lowering medication in the previous 12 months], distribution channel of medications [i.e., mail order or retail], and number of unique medications), health care costs (total, medical, and pharmacy [planand patient-paid]), and predicted adherence to IOP-lowering medication were also reported.

\section{Statistical Analyses}

Demographic and clinical characteristics obtained at baseline (Table 1) were as defined in the previous publication, ${ }^{15}$ reported using descriptive statistics, and compared across cohorts using a chi-square test (categorical variables) or 1-way analysis of variance (ANOVA; continuous variables). Mean PDC over the 6- and 12-month post-index periods was analyzed using 1-way ANOVA (intercohort comparisons). Post hoc analyses of the change in pre- to post-index mean PDC were compared using Student's paired t-test (intracohort comparisons). Intercohort comparisons of adherence were performed using a chi-square test. A $P$ value $<0.05$ was considered statistically significant.

\section{Sample Size Calculations}

A sample size of 400 patients per cohort was determined using a 2 -sided t-test with $80 \%$ power, a significance level of 0.05 $(P$ value), and an expected mean adherence improvement of $10 \%$ over a 12 -month time frame. ${ }^{3,10}$ To account for an estimated 30\% loss of study participants over time and ensure that the claims data analysis at the end of the observation period would include at least 400 patients per arm with continuous post-index enrollment, the sample size was set at 600 patients per intervention arm.

\section{Results}

\section{Patient Flow}

Of 60,621 patients who met the inclusion and exclusion criteria, 23,306 patients identified as potentially nonadherent, together with 2,955 physicians, were eligible for randomization (Figure 2). All patients sampled where the ratio of nonadherent patients to physician did not equal 3:1 were then excluded. Of the 6,675 and 2,225 remaining patients and physicians, respectively, 600 physicians in total (200 in each cohort) were randomly assigned to cohorts $\mathrm{A}, \mathrm{B}$, or $\mathrm{C}$, and 1,800 patients in total (600 in each cohort) of those physicians were automatically included in the same cohort without crossover.

Across cohorts, patient attrition rates at 6 months (i.e., after the second mailing) and 12 months post-index were $12.3 \%$ and $20.3 \%$, respectively, primarily due to disenrollment and removal after their physician was excluded due to an invalid address. Consistent with these data, physician attrition rates at 6 and 12 months post-index were $4.0 \%$ and $6.3 \%$, respectively, primarily due to undeliverable or returned mailings. At 12 months post-index, the numbers of patients and physicians remaining in each cohort were 502 and 199 (cohort A), 480 and 182 (cohort B), and 453 and 181 (cohort C), respectively.

\section{Patient Demographics and Characteristics}

At baseline, the majority of patients were female and Caucasian, lived in the South, and had a preferred provider organization (PPO) health plan (Table 1); average age was 75 years. All demographic and clinical variables were balanced across cohorts, except for geographic region, hyperlipidemia, and diagnosis of open-angle glaucoma by an ophthalmologist (Table 1). The physicians prescribing the most recent IOP-lowering medication in the identification period were primarily ophthalmologists (76.5\%-79.0\% across cohorts) and male (78.5\%-84.5\% across cohorts). At 12 months post-index, the characteristics of the remaining patient sample were comparable to those of the entire study cohort at baseline and comparable across cohorts; only 1 variable, geographic region, remained unbalanced across cohorts $(P<0.001)$. Physicians' characteristics also remained similar at 12 months post-index and across cohorts.

\section{PDC and Adherence}

No statistically significant differences in PDC were demonstrated across cohorts over the 12-month post-index period (Table 2). Consistent with this finding, there were no statistically significant differences in the proportion of adherent patients (characterized by a PDC $\geq 0.80$ ) across cohorts (Table 2). 
The Effect of an Educational Intervention on Adherence to Intraocular

Pressure-Lowering Medications in a Large Cohort of Older Adults with Glaucoma

\section{TABLE 1 Baseline Demographics and Clinical- and Prescription-Related Characteristics of Study Patients}

\begin{tabular}{|c|c|c|c|c|c|c|c|}
\hline & \multicolumn{2}{|c|}{$\begin{array}{c}\text { Cohort A } \\
(n=600)\end{array}$} & \multicolumn{2}{|c|}{$\begin{array}{l}\text { Cohort B } \\
(\mathrm{n}=600)\end{array}$} & \multicolumn{2}{|c|}{$\begin{array}{c}\text { Cohort C } \\
(\mathrm{n}=600)\end{array}$} & $P$ Value \\
\hline \multicolumn{8}{|l|}{ Demographics } \\
\hline Mean age (SD), years & 75.5 & $(5.9)$ & 75.6 & $(6.2)$ & 75.5 & $(6.0)$ & 0.876 \\
\hline Sex, $n(\%)$ & & & & & & & 0.239 \\
\hline Male & 252 & $(42.0)$ & 280 & $(46.7)$ & 273 & $(45.5)$ & \\
\hline Female & 348 & $(58.0)$ & 320 & (53.3) & 327 & $(54.5)$ & \\
\hline Race, n (\%) & & & & & & & 0.936 \\
\hline Caucasian & 472 & $(78.7)$ & 460 & $(76.7)$ & 477 & $(79.5)$ & \\
\hline African American & 107 & $(17.8)$ & 114 & $(19.0)$ & 101 & $(16.8)$ & \\
\hline Other & 21 & $(3.5)$ & 26 & (4.3) & 22 & $(3.7)$ & \\
\hline Geographic region, n (\%) & & & & & & & $<0.0001$ \\
\hline Northeast & 15 & $(2.5)$ & 12 & $(2.0)$ & 18 & $(3.0)$ & \\
\hline Midwest & 210 & $(35.0)$ & 135 & $(22.5)$ & 187 & $(31.2)$ & \\
\hline South & 308 & $(51.3)$ & 388 & $(64.7)$ & 323 & $(53.8)$ & \\
\hline West & 67 & $(11.2)$ & 65 & $(10.8)$ & 72 & $(12.0)$ & \\
\hline Health plan type, n (\%) & & & & & & & 0.115 \\
\hline Health maintenance organization & 202 & $(33.7)$ & 218 & $(36.3)$ & 226 & $(37.7)$ & \\
\hline Preferred provider organization & 324 & $(54.0)$ & 333 & $(55.5)$ & 319 & $(53.2)$ & \\
\hline Other & 74 & $(12.3)$ & 49 & $(8.2)$ & 55 & $(9.2)$ & \\
\hline Low-income subsidy status, $\mathrm{n}(\%)^{\mathrm{a}}$ & 61 & $(10.2)$ & 58 & $(9.7)$ & 59 & $(9.8)$ & 0.957 \\
\hline \multicolumn{8}{|l|}{ Clinical characteristics } \\
\hline \multicolumn{8}{|l|}{ Chronic conditions, $\mathrm{n}(\%)$} \\
\hline Hypertension & 465 & $(77.5)$ & 479 & $(79.8)$ & 465 & $(77.5)$ & 0.527 \\
\hline Hyperlipidemia & 439 & $(73.2)$ & 440 & $(73.3)$ & 474 & $(79.0)$ & 0.029 \\
\hline Diabetes & 198 & $(33.0)$ & 190 & $(31.7)$ & 222 & $(37.0)$ & 0.127 \\
\hline Congestive heart failure & 53 & $(8.8)$ & 47 & $(7.8)$ & 43 & $(7.2)$ & 0.561 \\
\hline Joint disorders & 126 & $(21.0)$ & 135 & $(22.5)$ & 124 & $(20.7)$ & 0.712 \\
\hline Mental disorders & 76 & $(12.7)$ & 68 & $(11.3)$ & 68 & $(11.3)$ & 0.710 \\
\hline Muscle weakness/neuropathy/movement disorders & 78 & $(13.0)$ & 87 & $(14.5)$ & 72 & $(12.0)$ & 0.436 \\
\hline \multicolumn{8}{|l|}{ Glaucoma-related variables, $\mathrm{n}(\%)$} \\
\hline Eye examb & 558 & $(93.0)$ & 546 & $(91.0)$ & 547 & $(91.2)$ & 0.378 \\
\hline Glaucoma-related eye examc & 401 & $(66.8)$ & 377 & $(62.8)$ & 402 & $(67.0)$ & 0.228 \\
\hline Glaucoma surgeryd & 19 & $(3.2)$ & 11 & $(1.8)$ & 16 & $(2.7)$ & 0.335 \\
\hline Open-angle glaucoma diagnosise & 358 & $(59.7)$ & 373 & $(62.2)$ & 402 & $(67.0)$ & 0.030 \\
\hline \multicolumn{8}{|l|}{ Prescription-related characteristics } \\
\hline New prescription users, $\mathrm{n}(\%)$ & 110 & $(18.3)$ & 124 & $(20.7)$ & 118 & $(19.7)$ & 0.593 \\
\hline Used mail order for first IOP-lowering medication in identification period, $\mathrm{n}(\%)$ & 513 & $(85.5)$ & 518 & $(86.3)$ & 520 & $(86.7)$ & 0.834 \\
\hline Number of unique medications, mean (SD) & 10.5 & $(6.1)$ & 10.6 & $(5.6)$ & 10.9 & $(6.0)$ & 0.378 \\
\hline Rx-Risk-V score, mean $(\mathrm{SD})^{\mathrm{f}}$ & 6.0 & $(3.2)$ & 6.1 & $(2.8)$ & & $(3.0)$ & 0.751 \\
\hline Medical costs (\$), mean (SD) & 6,466 & $(10,335)$ & 6,928 & $(10,857)$ & 7,778 & $13,968)$ & 0.150 \\
\hline Prescription costs (\$), mean (SD) & 2,145 & $(3,831)$ & 2,005 & $(3,189)$ & 2,216 & $(4,627)$ & 0.637 \\
\hline Probability of patients being nonadherent, mean \% (SD)g & 63 & $(8)$ & 63 & (9) & 63 & (9) & 0.629 \\
\hline \multicolumn{8}{|c|}{ 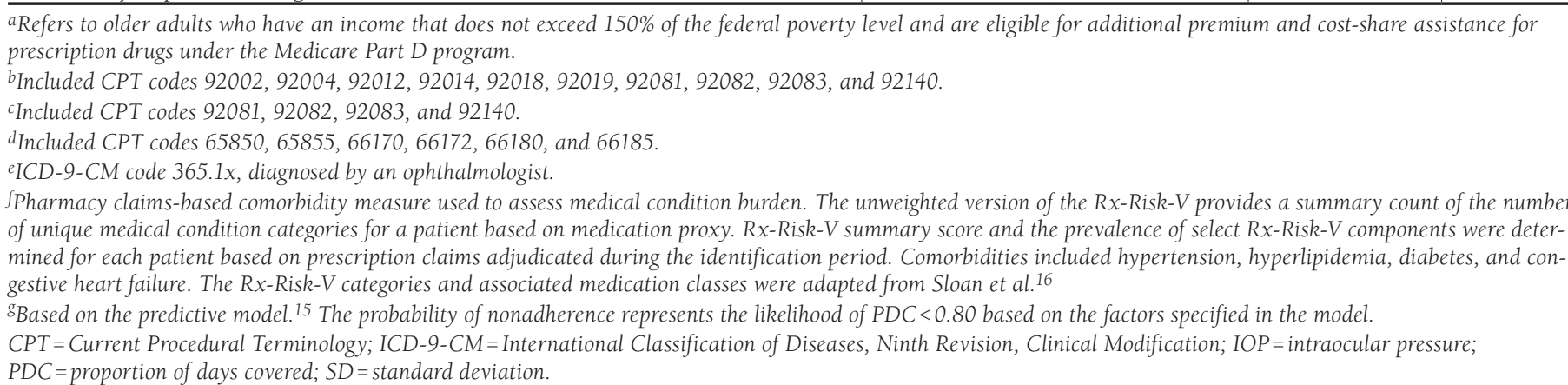 } \\
\hline
\end{tabular}


The Effect of an Educational Intervention on Adherence to Intraocular

Pressure-Lowering Medications in a Large Cohort of Older Adults with Glaucoma

\section{FIGURE 2 Patient Selection Flow Diagram}

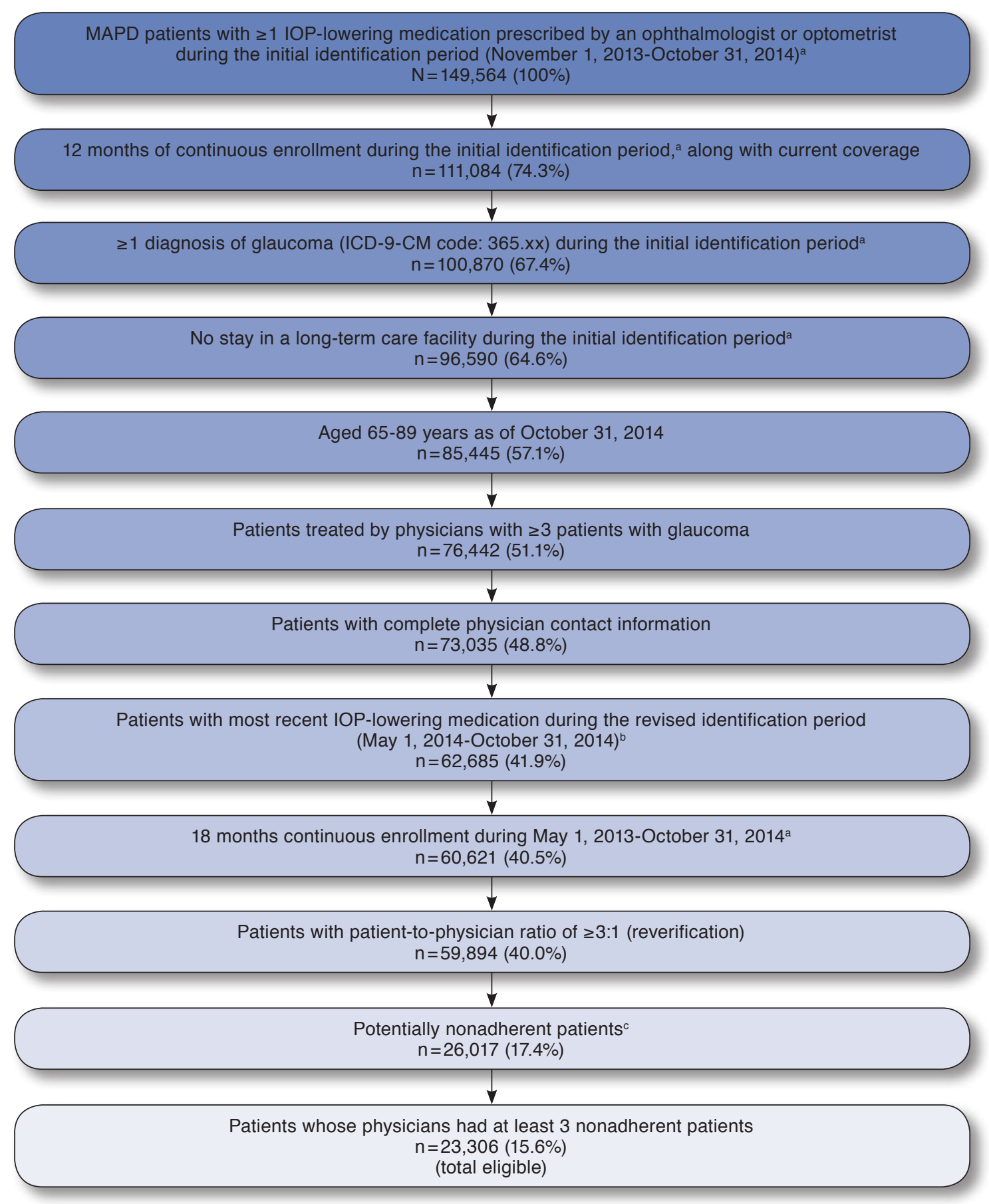

${ }^{a}$ This identification period was later modified to May 1, 2014-October 31, 2014, to capture patients with the most recent IOP prescription closer to the time of the intervention. It was also required that patients have continuous enrollment for 18 months before the identification date (October 31, 2014), which allowed for a full 12 months of claims data for each patient before the most recent IOP medication claim in the modified identification period.

${ }^{b}$ Modified criteria.

CThese are patients who were identified by the predictive model as having $a \geq 50 \%$ likelihood of being nonadherent (PDC $<0.80)$ based on the specified factors. ICD-9-CM = International Classification of Diseases, Ninth Revision, Clinical Modification; IOP = intraocular pressure; MAPD= Medicare Advantage Prescription Drug plan; $P D C=$ proportion of days covered. 
The Effect of an Educational Intervention on Adherence to Intraocular

Pressure-Lowering Medications in a Large Cohort of Older Adults with Glaucoma

TABLE 2 PDC and Adherence over the Baseline Period and 6-Month and 12-Month Post-Index Periods

\begin{tabular}{|c|c|c|c|c|c|c|c|c|c|}
\hline \multirow[b]{3}{*}{ Cohorts } & \multirow{2}{*}{\multicolumn{3}{|c|}{ Baseline Period ${ }^{a}$}} & \multirow{2}{*}{\multicolumn{3}{|c|}{ 6-Month/12-Month Post-Index Period }} & \multirow[b]{3}{*}{$\begin{array}{l}\text { PDC Change } \\
\text { Mean (SD) }\end{array}$} & \multirow{2}{*}{\multicolumn{2}{|c|}{$\begin{array}{c}P \text { Value } \\
\begin{array}{c}\text { Intercohort Comparison } \\
\text { (Post-Index) }\end{array}\end{array}$}} \\
\hline & & & & & & & & & \\
\hline & $\mathrm{N}$ & $\begin{array}{c}\text { PDC } \\
\text { Mean (SD) }\end{array}$ & $\begin{array}{c}\text { Adherenceb }^{\mathrm{b}} \\
\text { n (\%) }\end{array}$ & $\mathrm{N}$ & $\begin{array}{c}\text { PDC } \\
\text { Mean (SD) }\end{array}$ & $\begin{array}{c}\text { Adherence }^{\mathrm{b}} \\
\text { n (\%) }\end{array}$ & & PDC & Adherence $^{b}$ \\
\hline \multicolumn{10}{|c|}{ 6-month post-index period } \\
\hline A & 545 & $0.56(0.30)$ & $141(25.9)$ & 545 & $0.52(0.32)$ & $134(24.6)$ & $-0.04(0.29)$ & \multirow{3}{*}{$0.636^{c}$} & \multirow{3}{*}{$0.870^{c}$} \\
\hline $\mathrm{B}$ & 522 & $0.55(0.31)$ & $132(25.3)$ & 522 & $0.52(0.33)$ & $128(24.5)$ & $-0.03(0.29)$ & & \\
\hline $\mathrm{C}$ & 512 & $0.54(0.31)$ & $128(25.0)$ & 512 & $0.54(0.32)$ & $132(25.8)$ & $-0.02(0.27)$ & & \\
\hline \multicolumn{10}{|c|}{ 12-month post-index period } \\
\hline A & 502 & $0.56(0.26)$ & $110(21.9)$ & 502 & $0.54(0.30)$ & $128(25.5)$ & $-0.02(0.26)$ & \multirow{3}{*}{$0.921^{c}$} & \multirow{3}{*}{$0.773^{c}$} \\
\hline $\mathrm{B}$ & 480 & $0.55(0.26)$ & $100(20.8)$ & 480 & $0.53(0.30)$ & $114(23.8)$ & $-0.02(0.27)$ & & \\
\hline C & 453 & $0.55(0.26)$ & $98(21.6)$ & 453 & $0.54(0.29)$ & $108(23.8)$ & $-0.01(0.23)$ & & \\
\hline \multicolumn{10}{|c|}{$\begin{array}{l}\text { aDefined as the } 12 \text {-month period immediately preceding the bas } \\
\text { bDefined as } P D C \geq 0.80 \text {. } \\
\text { 'Comparison across all } 3 \text { cohorts. } \\
P D C=\text { proportion of days covered; SD = standard deviation. }\end{array}$} \\
\hline
\end{tabular}

Additional analyses comparing pre- to post-index changes in PDC did not reveal any statistically significant differences across cohorts $(P>0.05$ in all cases; Table 2$)$ or within cohorts.

\section{Discussion}

The primary objectives of this study were to identify older adults who were potentially nonadherent to prescribed IOPlowering therapy and to evaluate the effect of patient- and physician-centric interventions on patient adherence to treatment in this population based on prescription fill data. The study used a multifaceted approach specifically adapted for patients and their physicians (mostly ophthalmologists) and intended to promote patient education and involvement of treating physicians, the effect of which on adherence has been reported in other studies. ${ }^{21,22}$ However, despite provision of written educational materials to both audiences and patientspecific clinical and prescribing information to physicians over a 12-month period in an at-risk population, adherence to treatment did not significantly change. Our findings illustrate the difficulty of improving adherence to treatment using interventions designed to be practical and applicable in a large health plan when the disease is chronic and typically asymptomatic until late stages.

Other published investigations of various patient-centric strategies aimed at improving adherence in glaucoma have yielded mixed results, although they included considerably fewer patients ( $\mathrm{n}=11$ to 805 ) than the present study $(\mathrm{n}=1,800))^{9-11,23-34}$ Two studies employed automated telecommunications such as texts and voice messages to send reminders, for example, about taking medications or upcoming appointments. ${ }^{9,29}$ In other studies, print materials and letters were also included as part of the patient-centric intervention, but poor health literacy about glaucoma and the importance of adherence to treatment may have lessened their effect, as discussed by other groups. ${ }^{11,26,29,35,36}$ The interventions that reportedly had the greatest effect on adherence to IOP-lowering treatment utilized interactive approaches such as telephone calls or face-to-face meetings, along with coaching or visual education materials (e.g., demonstrations and videos). ${ }^{10,11,23,24,33}$ Regardless, adherence to treatment increased by only $\leq 16 \%$ compared with the respective baseline or control group.

Consistent with observations reported in studies of patientcentric interventions, studies that included a physician-centric intervention to improve patient adherence to treatment have also produced mixed results. ${ }^{37-40}$ These interventions comprised, for example, faxing prescribing physicians to alert them of patients with gaps of $>10$ days in their prescription refill, and educational materials \pm patient-specific computerized alerts. ${ }^{37,38}$ The intervention evaluated herein provided physicians with clinical and prescription information that was patient-specific and could be used for individual patient counseling or follow-up, as well as educational materials on glaucoma for both patients and physicians. Although 1 of the previously published studies was similar to ours in terms of the type of intervention (educational mailings) and being directed at both patients and physicians, it incorporated additional improvement initiatives (disease management programs), thereby complicating attempts to determine the contribution of the educational intervention to the observed improvement in adherence. ${ }^{39}$

Whether our patient-centric intervention would have benefited from inclusion of a more interactive component is unclear. However, the feasibility and cost-effectiveness of extending the use of interactive, adherence-fostering approaches to all 
patients who are potentially nonadherent to their glaucoma medication (23,306 with 2,995 physicians in this study alone) should be taken into consideration. Even if automated, texts, emails, and/or voicemails sent 1,2 , or 3 times daily (depending on the medication class) to remind patients to use their IOP-lowering medication would require tracking (potentially making it impractical in large populations) and would not be expected to help alleviate the instillation-related component of nonadherence (for example). ${ }^{14}$ Moreover, adherence to ocular treatment in elderly populations is often further compromised by the concomitant use of systemic medications or comorbidities such as arthritis. These constraints highlight the need for effective, longer-term glaucoma therapies with improved tolerability profiles that do not need to rely on the patients' compliance or physicians' reminders to ensure adherence. The development of sustained-release drug delivery systems and minimally invasive glaucoma surgery devices thus has the potential to overcome issues related to nonadherence to a prescribed dosing regimen. .1-53 $^{4}$

It is also possible that interventions involving a team approach and collaboration between physicians and pharmacists might have a greater effect on adherence to medication. Such interventions could include emails, texts, or voicemails from the pharmacist alerting patients with gaps of $>10$ days in their prescription refill (which could be more effective than alerting providers of patients with such gap) ${ }^{37}$ and/or encouraging patients to sign up for auto-refills. Educational materials such as those used in this study could be emailed to patients, which (compared with print versions) would allow those with potential visual impairment (glaucoma-related or not) to adjust the font size, brightness, and/or contrast as needed and facilitate reading of the information. It should also be noted, however, that if patients do not see well enough to read written information (or have co-conditions such as arthritis), instillation of eye drops could be an issue. In such cases, designating a family member to help foster adherence behavior may be helpful. ${ }^{54,55}$ Patients could also be asked to provide a reason for their nonadherence to treatment before their prescriptions are released, based on a recent study in which adherence to guidelines improved if health care practitioners had to provide a reason for nonadherence. ${ }^{56}$ Results from a study investigating the effects of incentives on adherence to glaucoma treatment (i.e., $50 \%$ or $25 \%$ rebate on glaucoma-related health care costs for adherence over at least $90 \%$ or $75 \%$ of days, respectively, based on a medication event monitoring system) should be very informative as well..$^{57}$ Future studies might benefit from investigating combinations of the aforementioned interventions.

\section{Limitations}

This study has some limitations to consider. The effect of clustering was not evaluated, and identification of potentially nonadherent patients was based on a predictive model. ${ }^{15}$ Although the model was developed and validated in a population of patients with glaucoma from the same Humana research database as this study population, differences in demographics and clinical- and/or prescription-related characteristics of the 2 populations due to variations in patient populations over time may have affected its discriminative ability. For example, approximately $35 \%, 54 \%$, and $10 \%$ of patients had a health maintenance organization, $\mathrm{PPO}$, or other plan in this study compared with $54 \%, 28 \%$, and $18 \%$ in the previous study, respectively. ${ }^{15}$ Similarly, the proportions of new prescription users and mail orders for the first IOP-lowering prescription were approximately $20 \%$ and $86 \%$ in this study compared with $31 \%$ and $35 \%$ in the previous study, respectively. ${ }^{15}$ It should be noted, however, that these numerical differences have not been tested for statistical significance.

Although most large Medicare providers offer some type of mail order benefit to patients, there may be some that do not, which could also affect the discriminative ability of the model in other studies. Moreover, patients were eligible for intervention if their probability of nonadherence was $\geq 50 \%$; while this value was selected to capture varying levels of potential nonadherence, a narrower range might have produced statistically significant differences across cohorts.

It is also worth noting that the intervention materials were sent by mail (although there was no means of verifying whether patients and physicians received or read them) and that, compared with the PDC, a medication event monitoring system might have been better suited to measure adherence. The costeffectiveness of the latter approach in a real-world clinical setting, however, should be determined. In addition, the actions of physicians in cohorts B and C were not recorded, which may have contributed to the lack of statistically significantly different results between those cohorts.

Although the modified identification time frame spanned May 1, 2014-October 31, 2014, data extraction did not occur until early 2015 because of the lag in enrollment and medical claims data. Therefore, after data extraction, patient/physician identification, and preparation of the mailings, there was a gap between the dates used for identification of nonadherent patients and the baseline mailing, during which adherence could have changed. However, nonadherence across cohorts was measured and verified by utilizing baseline data in the 12 months immediately preceding the first intervention (i.e., April 2014-March 2015), mitigating this limitation's effect on the findings.

This study included a variety of patients with glaucoma and set no conditions on the time since diagnosis, time on treatment, or type of IOP-lowering medication; it may be useful, however, to investigate these subsets of patients in future studies. New users of IOP-lowering medication constituted approximately $20 \%$ of the patient sample, leaving $80 \%$ with previous or continuing treatment. Since adherence to IOP-lowering 


\section{The Effect of an Educational Intervention on Adherence to Intraocular Pressure-Lowering Medications in a Large Cohort of Older Adults with Glaucoma}

medication has been reported to decrease to 56\%-57\% within the first year of treatment, patients may have already reached a point at which the effect of any intervention would have been limited. ${ }^{5,58,59}$ Differences in adherence to IOP-lowering drugs of the same class have also been reported, ${ }^{60}$ but this factor was not considered in this study. Likewise, the study did not take into account behavioral or psychological factors that may affect adherence. ${ }^{61,62}$

Finally, limitations common to studies using administrative claims data apply to this case, such as potential errors in claims coding. In addition, the data used were from patients enrolled with a single health care company and, as such, results may not be generalizable to other populations; however, Humana is a large national health care company with broad geographic representation.

\section{Conclusions}

Findings from this prospective, randomized, and controlled study show that patient- and physician-centric multifaceted informational and educational mailings were not effective in improving adherence to IOP-lowering treatment in this population of elderly patients with glaucoma, underscoring the challenge of finding novel mechanisms for improving adherence in glaucoma, an irreversible disease that requires early and lifelong therapy despite being asymptomatic until late stages.

\section{Authors}

RICHARD FISCELLA, PharmD, MPH, Allergan plc, Irvine, California. ELEANOR CAPLAN, PharmD, PhD; PRAVIN KAMBLE, RPh, PhD; SUVAPUN BUNNIRAN, PhD; and CLAUDIA URIBE, MD, PHA, PhD, Comprehensive Health Insights, Louisville, Kentucky. HITESH CHANDWANI, MBBS, PhD, Allergan Singapore Pte. Ltd., Singapore.

AUTHOR CORRESPONDENCE: Richard Fiscella, PharmD, MPH, Director, Managed Care Scientific, Ophthalmology, Allergan plc, 2525 Dupont Dr., Irvine, CA 92612. E-mail: Fiscella_Rick@Allergan.com.

\section{DISCLOSURES}

This study was sponsored by Allergan plc (Dublin, Ireland). Fiscella and Chandwani are employees of Allergan plc. Caplan, Kamble, Bunniran, and Uribe are employees of Comprehensive Health Insights, a Humana company. The authors did not receive honoraria or other payments for authorship.

\section{ACKNOWLEDGMENTS}

The authors thank Raymond A. Harvey and Jennifer Hayden (Comprehensive Health Insights) for their support and assistance throughout this study. Writing and editorial assistance was provided to the authors by Michele Jacob, PhD, CMPP, and Andrew Fitton, PhD, of Evidence Scientific Solutions (Philadelphia, PA), and funded by Allergan plc.

\section{REFERENCES}

1. American Academy of Ophthalmology. Preferred practice pattern in primary open-angle glaucoma. 2015. Available at: https://www.aao.org/preferred-practice-pattern/primary-open-angle-glaucoma-ppp-2015. Accessed May 12, 2018.

2. Nordstrom BL, Friedman DS, Mozaffari E, Quigley HA, Walker AM. Persistence and adherence with topical glaucoma therapy. Am J Ophthalmol. 2005;140(4):598.el-598.ell.

3. Friedman DS, Quigley HA, Gelb L, et al. Using pharmacy claims data to study adherence to glaucoma medications: methodology and findings of the Glaucoma Adherence and Persistency Study (GAPS). Invest Ophthalmol Vis Sci. 2007;48(11):5052-57.

4. Yeaw J, Benner JS, Walt JG, Sian S, Smith DB. Comparing adherence and persistence across 6 chronic medication classes. J Manag Care Pharm. 2009;15(9):728-40.

5. Reardon G, Kotak S, Schwartz GF. Objective assessment of compliance and persistence among patients treated for glaucoma and ocular hypertension: a systematic review. Patient Prefer Adherence. 2011;5:441-63.

6. Stryker JE, Beck AD, Primo SA, et al. An exploratory study of factors influencing glaucoma treatment adherence. J Glaucoma. 2010;19(1):66-72.

7. Newman-Casey PA, Blachley T, Lee PP, Heisler M, Farris KB, Stein JD. Patterns of glaucoma medication adherence over four years of follow-up. Ophthalmology. 2015;122(10):2010-21.

8. Sleath B, Blalock S, Covert D, et al. The relationship between glaucoma medication adherence, eye drop technique, and visual field defect severity. Ophthalmology. 2011;118(12):2398-402.

9. Boland MV, Chang DS, Frazier T, Plyler R, Jefferys JL, Friedman DS. Automated telecommunication-based reminders and adherence with oncedaily glaucoma medication dosing: the automated dosing reminder study. JAMA Ophthalmol. 2014;132(7):845-50.

10. Okeke CO, Quigley HA, Jampel HD, et al. Interventions improve poor adherence with once daily glaucoma medications in electronically monitored patients. Ophthalmology. 2009;116(12):2286-93

11. Pizzi LT, Tran J, Shafa A, et al. Effectiveness and cost of a personalized reminder intervention to improve adherence to glaucoma care. Appl Health Econ Health Policy. 2016;14(2):229-40.

12. Cedrone C, Mancino R, Cerulli A, Cesareo M, Nucci C. Epidemiology of primary glaucoma: prevalence, incidence, and blinding effects. Prog Brain Res. 2008;173:3-14.

13. Tham YC, Li X, Wong TY, Quigley HA, Aung T, Cheng CY. Global prevalence of glaucoma and projections of glaucoma burden through 2040: a systematic review and meta-analysis. Ophthalmology. 2014;121(11):2081-90.

14. Newman-Casey PA, Robin AL, Blachley T, et al. The most common barriers to glaucoma medication adherence: a cross-sectional survey. Ophthalmology. 2015;122(7):1308-16.

15. Sheer R, Bunniran S, Uribe C, Fiscella RG, Patel VD, Chandwani HS. Predictors of nonadherence to topical intraocular pressure reduction medications among Medicare members: a claims-based retrospective cohort study. J Manag Care Spec Pharm. 2016;22(7):808-17a. Available at: https:// www.jmcp.org/doi/10.18553/jmcp.2016.22.7.808.

16. Sloan KL, Sales AE, Liu CF, et al. Construction and characteristics of the RxRisk-V: a VA-adapted pharmacy-based case-mix instrument. Med Care. 2003;41(6):761-74

17. Jackson A, ed. Understanding and Living with Glaucoma. San Francisco, CA: Glaucoma Research Foundation; 2016.

18. Campbell JH, Schwartz G, LaBounty B, Kowalski J, Patel VD. Comparison of adherence and persistence with bimatoprost $0.01 \%$ versus bimatoprost $0.03 \%$ topical ophthalmic solutions. Curr Med Res Opin. 2013:29(9):1201-09. 


\section{The Effect of an Educational Intervention on Adherence to Intraocular Pressure-Lowering Medications in a Large Cohort of Older Adults with Glaucoma}

19. Fiscella RG, Green A, Patuszynski DH, Wilensky J. Medical therapy cost considerations for glaucoma. Am J Ophthalmol. 2003;136(1):18-25.

20. Rylander NR, Vold SD. Cost analysis of glaucoma medications. Am J Ophthalmol. 2008;145(1):106-13

21. Cohen Castel O, Keinan-Boker L, Geyer O, Milman U, Karkabi K. Factors associated with adherence to glaucoma pharmacotherapy in the primary care setting. Fam Pract. 2014;31(4):453-61.

22. Sleath B, Carpenter DM, Blalock SJ, et al. Applying the resources and supports in self-management framework to examine ophthalmologist-patient communication and glaucoma medication adherence. Health Educ Res. 2015;30(5):693-705.

23. Dreer LE, Owsley C, Campbell L, Gao L, Wood A, Girkin CA. Feasibility, patient acceptability, and preliminary efficacy of a culturally informed, health promotion program to improve glaucoma medication adherence among African Americans: "Glaucoma management optimism for African Americans living with glaucoma" (GOAL). Curr Eye Res. 2016;41(1):50-58

24. Djafari F, Lesk MR, Giguère CÉ, Siam G, Freeman EE. Impact of a brief educational intervention on glaucoma persistence: a randomized controlled clinical trial. Ophthalmic Epidemiol. 2015;22(6):380-86.

25. Cate H, Bhattacharya D, Clark A, Fordham R, Holland R, Broadway DC. Improving adherence to glaucoma medication: a randomised controlled trial of a patient-centred intervention (The Norwich Adherence Glaucoma Study). BMC Ophthalmol. 2014;14:32.

26. Beckers HJ, Webers CA, Busch MJ, Brink HM, Colen TP, Schouten JS; The Dutch Adherence Study Group. Adherence improvement in Dutch glaucoma patients: a randomized controlled trial. Acta Ophthalmol. 2013;91(7):610-18

27. Richardson C, Brunton L, Olleveant N, et al. A study to assess the feasibility of undertaking a randomized controlled trial of adherence with eye drops in glaucoma patients. Patient Prefer Adherence. 2013;7:1025-39.

28. Lim MC, Watnik MR, Imson KR, Porter SM, Granier AM. Adherence to glaucoma medication: the effect of interventions and association with personality type. J Glaucoma. 2013;22(6):439-46.

29. Glanz K, Beck AD, Bundy L, et al. Impact of a health communication intervention to improve glaucoma treatment adherence. Results of the interactive study to increase glaucoma adherence to treatment trial. Arch Ophthalmol. 2012;130(10):1252-58.

30. Muir KW, Ventura A, Stinnett SS, Enfiedjian A, Allingham RR, Lee PP. The influence of health literacy level on an educational intervention to improve glaucoma medication adherence. Patient Educ Couns. 2012;87(2):160-64.

31. Lunnela J, Kääriäinen M, Kyngäs H. Web-based intervention for improving adherence of people with glaucoma. J Nurs Healthcare Chronic Illness. 2011;3(2):119-29.

32. Chen X, Chen Y, Sun X. Notable role of glaucoma club on patients' knowledge of glaucoma. Clin Exp Ophthalmol. 2009;37(6):590-94.

33. Sheppard J, Warner J, Kelley K. An evaluation of the effectiveness of a nurse-led glaucoma monitoring clinic. Ophthalmic Nurs Int J Ophthalmic Nurs. 2003;7(2):15-21.

34. Rendell J. Effect of health education on patients' beliefs about glaucoma and compliance. Insight. 2000;25(4):112-18

35. Muir KW, Christensen L, Bosworth HB. Health literacy and glaucoma. Curr Opin Ophthalmol. 2013;24(2):119-24.

36. Peralta E, Muir KW, Rosdahl JA. Systematic review of knowledge assessments for glaucoma patients. Semin Ophthalmol. 2018;33(3):377-88.

37. Bambauer KZ, Adams AS, Zhang F, et al. Physician alerts to increase antidepressant adherence: fax or fiction? Arch Intern Med. 2006;166(5):498-504.

38. Roumie CL, Elasy TA, Greevy R, et al. Improving blood pressure control through provider education, provider alerts, and patient education: a cluster randomized trial. Ann Intern Med. 2006;145(3):165-75.
39. Jing S, Naliboff A, Kaufman MB, Choy M. Descriptive analysis of mail interventions with physicians and patients to improve adherence with antihypertensive and antidiabetic medications in a mixed-model managed care organization of commercial and Medicare members. J Manag Care Pharm. 2011;17(5):355-66. Available at: https://www.jmcp.org/doi/10.18553/ jmcp.2011.17.5.355.

40. Carpenter DM, Tudor GE, Sayner R, et al. Exploring the influence of patient-provider communication on intraocular pressure in glaucoma patients. Patient Educ Couns. 2015;98(12):1558-67.

41. Brandt JD, Sall K, DuBiner H, et al. Six-month intraocular pressure reduction with a topical bimatoprost ocular insert: results of a phase II randomized controlled study. Ophthalmology. 2016;123(8):1685-94.

42. Cheng YH, Tsai TH, Jhan YY, et al. Thermosensitive chitosan-based hydrogel as a topical ocular drug delivery system of latanoprost for glaucoma treatment. Carbohydr Polym. 2016;144:390-99.

43. Chiang B, Kim YC, Doty AC, Grossniklaus HE, Schwendeman SP, Prausnitz MR. Sustained reduction of intraocular pressure by supraciliary delivery of brimonidine-loaded poly(lactic acid) microspheres for the treatment of glaucoma. J Control Release. 2016;228:48-57.

44. Foureaux G, Franca JR, Nogueira JC, et al. Ocular inserts for sustained release of the angiotensin-converting enzyme 2 activator, diminazene aceturate, to treat glaucoma in rats. PLoS One. 2015;10(7):e0133149.

45. Ibrahim MM, Abd-Elgawad AH, Soliman OA, Jablonski MM. Natural bioadhesive biodegradable nanoparticle-based topical ophthalmic formulations for management of glaucoma. Transl Vis Sci Technol. 2015;4(3):12.

46. Katiyar S, Pandit J, Mondal RS, et al. In situ gelling dorzolamide loaded chitosan nanoparticles for the treatment of glaucoma. Carbohydr Polym. 2014;102:117-24.

47. Kim J, Kudisch M, Mudumba S, et al. Biocompatibility and pharmacokinetic analysis of an intracameral polycaprolactone drug delivery implant for glaucoma. Invest Ophthalmol Vis Sci. 2016;57(10):4341-46

48. Manickavasagam D, Wehrung D, Chamsaz EA, et al. Assessment of alkoxylphenacyl-based polycarbonates as a potential platform for controlled delivery of a model anti-glaucoma drug. Eur J Pharm Biopharm. 2016;107:56-66.

49. Natarajan JV, Darwitan A, Barathi VA, et al. Sustained drug release in nanomedicine: a long-acting nanocarrier-based formulation for glaucoma. ACS Nano. 2014;8(1):419-29.

50. Voss K, Falke K, Bernsdorf A, et al. Development of a novel injectable drug delivery system for subconjunctival glaucoma treatment. J Control Release. 2015;214:1-11.

51. Samuelson TW, Katz LJ, Wells JM, Duh YJ, Giamporcaro JE. Randomized evaluation of the trabecular micro-bypass stent with phacoemulsification in patients with glaucoma and cataract. Ophthalmology. 2011;118(3):459-67.

52. Vold S, Ahmed I, Craven ER, et al. Two-year COMPASS trial results: supraciliary microstenting with phacoemulsification in patients with openangle glaucoma and cataracts. Ophthalmology. 2016;123(10):2103-12.

53. Lewis RA. Ab interno approach to the subconjunctival space using a collagen glaucoma stent. J Cataract Refract Surg. 2014:40(8):1301-06.

54. Morgan C, McBeth J, Cordingley L, et al. The influence of behavioural and psychological factors on medication adherence over time in rheumatoid arthritis patients: a study in the biologics era. Rheumatology (Oxford). 2015;54(10):1780-91

55. Pladevall M, Brotons C, Gabriel R, et al. Multicenter cluster-randomized trial of a multifactorial intervention to improve antihypertensive medication adherence and blood pressure control among patients at high cardiovascular risk (the COM99 study). Circulation. 2010;122(12):1183-91.

56. Kooij FO, Klok T, Preckel B, Hollmann MW, Kal JE. The effect of requesting a reason for non-adherence to a guideline in a long running automated reminder system for PONV prophylaxis. Appl Clin Inform. 2017:8(1):313-21 
The Effect of an Educational Intervention on Adherence to Intraocular

Pressure-Lowering Medications in a Large Cohort of Older Adults with Glaucoma

57. Bilger M, Wong TT, Howard KL, et al. Study on Incentives for Glaucoma Medication Adherence (SIGMA): study protocol for a randomized controlled trial to increase glaucoma medication adherence using value pricing. Trials. 2016;17(1):316

58. Feehan M, Munger MA, Cooper DK, et al. Adherence to glaucoma medications over 12 months in two US community pharmacy chains. J Clin Med. 2016;5(9):pii:E79

59. Schwartz GF, Quigley HA. Adherence and persistence with glaucoma therapy. Surv Ophthalmol. 2008;53(6 Suppl 1):S57-S68.
60. Campbell JH, Schwartz GF, LaBounty B, Kowalski JW, Patel VD. Patient adherence and persistence with topical ocular hypotensive therapy in realworld practice: a comparison of bimatoprost $0.01 \%$ and travoprost Z $0.004 \%$ ophthalmic solutions. Clin Ophthalmol. 2014;8:927-35.

61. McDonald HP, Garg AX, Haynes RB. Interventions to enhance patient adherence to medication prescriptions: scientific review. JAMA. 2002:288(22):2868-79.

62. Williams A, Manias E, Walker R. Interventions to improve medication adherence in people with multiple chronic conditions: a systematic review. J Adv Nurs. 2008;63(2):132-43. 